\title{
Johannes Kepler and his making of the Rudolphine Tables
}

\author{
Ref. 6220Nov21 (revised accepted version) - for Mathematical Gazette \\ 23.620
}

\section{Background and Motivation}

This article is about the many complicated tasks that one mathematician had to carry out, and the barriers he had to overcome, to publish one very important book in the history of applied mathematics.

Concerning the sources I have used, the mathematical details of Kepler's work on the solar system and the heliocentric model of Copernicus, are in Linton [1]. For Kepler's biography see Caspar [2], and a recent double biography of Kepler and Tycho Brahe, by Ferguson [3]. Arthur Koestler [4] wrote a very readable account of the discoveries of Copernicus, Galilieo and Kepler, but for the latter he draws heavily on the earlier scholarship of Caspar [2]. From now on we will abbreviate Kepler to K, after Joseph K, the long-suffering defendant in Franz Kafka's novel The Trial. Also $K$ or $k$ is a symbol often used for something unchanging in time (like Kepler's determination). An example of a constant $k$ appears below.

Johannes Kepler [1571-1630], K, spent his long life of creative hard work as a mathematical astronomer. Although better known among astronomers than mathematicians, the story of $\mathrm{K}$ shows that he repeatedly used mathematics to help understand the world. For example, K discovered a class of semi-regular polyhedra; he proved significant results to caluclate the volume of revolution of a plane figure about an axis; and below we show he was among the first to use logarithms in scientific work. Kepler's eyesight was too poor for him to be a professional observer, but he did make some celestial measurements. His collaboration with the flamboyant aristocratic astronomer Tycho Brahe [1546-1601] gave him access to the best measurements available, because Brahe had built the largest naked-eye instruments in Europe which could be pointed accurately at the night sky. This was in the days when telescopes were either unavailable or, from 1610 onwards, the new ones were so troubled by aberrations that they were no good for accurate star-positioning work.

When Tycho Brahe died K inherited a mass of manuscripts containing Brahe's theory of the solar system and, more importantly, his very accurate positions for over 700 stars and the planets. But K's possession of these precious scientific papers was contested by the Brahe family, of which more later. Tycho's data was vital to K's undertaking of a great task, and it took K the rest of his active life to complete it. He came under increasing pressure from fellow scientists to publish an accurate set of star-tables, because the then current Alphonsine Tables and Prutenic Tables were hopelessly out of date, error prone, and their methods made poor predictions of planetary positions. This was a bad state of the art for a wide class of practitioners and theoreticians who knew the old tables were flawed. For example, navigators at sea relying on faulty tables made fatal mistakes. Explorers, map-makers and astrologers were just some of the other skilled workers who needed better tables. I include astrologers because $\mathrm{K}$ himself cast horoscopes based on the arrangement of the night sky at the exact time of a client's birth. Making astrological charts was sometimes the only cash income K received to support his growing family. Despite K's impressive job title, Imperial Mathematician which he held from 16001612, Emperor Rudolph II rarely paid him. Rudolph nominally employed both Tycho and K, until the emperor's death in 1612. The word Rudolphine is derived from Rudolph's patronage of the two men during their period of closest collaboration.

Kepler's book of mathematical astronomy, explaining the revolutionary work of Nicolas Copernicus and Brahe's data is now known as the Rudolphine Tables [5] in my title. The word "making" in my title also needs explanation. Throughout literary history an author has been expected to deliver a manuscript, of greater or lesser creativity, more or less on time to a publisher. It's rare for the author to also: caste special type for symbols; recruit a specialist printer and apprentices (he did this twice); buy bales of paper for the print run; travel many miles on foot and horseback to raise money to fund the enterprise; proof-check the pages as they came fresh from the press; risk his life under fire while getting the copies printed; transport copies to a book fair; haggle the price; sell hundreds of copies to booksellers; and post complementary copies to libraries and friends abroad. K did all these things in the face of sometimes 


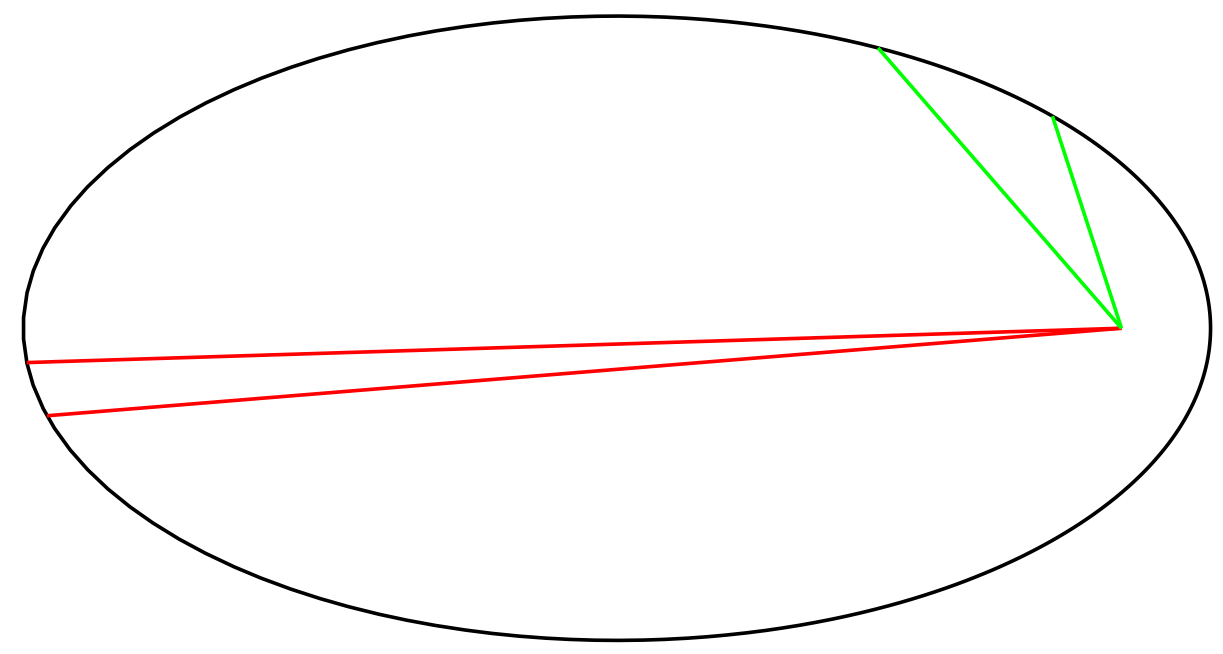

Figure 1: The orbit has the Sun at one focus. Pairs of green and red lines mark regions swept out by the Sun-planet line in equal times; the two regions have equal area.

violent personal disagreements, with his beloved family in tow, sometimes in the midst of plague and war, enduring a house-fire in which he lost nearly everything, but saving his family, himself and his precious manuscript. We tell this story in the next section.

K's labours on paper involved him computing by hand, from his own laws of planetary motion, the past and future positions of the then known planets: Mercury, Venus, Mars, Jupiter, Saturn. Kepler's Three Laws are: first, a planet's orbit is an ellipse with the Sun at one focus; second, a straight line drawn from the centre of the Sun to the planet sweeps out equal areas in equal times; third, if $R$ is the mean distance of a planet from the Sun and if it takes time $T$ to complete one orbit, then

$$
R^{3}=k T^{2}
$$

where $k$ has the same value for all bodies which orbit the Sun. See Figure 1.

We digress a little on this applied mathematics. Thanks to Isaac Newton's work 1684-7, published in his Principia, we now know that Kepler's laws are not just empirical facts but the mathematical consequences of the force of gravity acting between the mass of a planet and the mass of the Sun. Newton eventually proved that spherical masses attract each exactly as point-masses. A consequence of writing force equals mass times acceleration, along with Newton's law of gravity, is the existence of an invariant $k$, where

$$
k=G M .
$$

Here, to 3 significant figures, $G=6.67 \times 10^{-11} \mathrm{Nm}^{2} \mathrm{~kg}^{-2}$ is the universal gravitational constant, and $M=1.99 \times 10^{30} \mathrm{~kg}$ is the mass of the Sun. Consequently, for our solar system $k=1.33 \times 10^{20} \mathrm{~m}^{3} \mathrm{~s}^{-2}$. Of course, $k=R^{3} T^{-2}$ has different values for other orbital systems, such as the 79 (or more) moons of Jupiter: observing the period and mean radius of one moon lets us weigh Jupiter. A more striking example comes from new techniques of measurement analysis. These can infer the period $T$ of an invisible exoplanet, orbiting a remote star, from the wobble the planet induces in the star. An estimate of the star's mass can be made independently from a mass-brightness relationship. Then eqs (1) and (2) give astronomers the mean radius $R$ of the orbit. And all this with the planet being invisible to telescopes.

Among astronomers, $\mathrm{K}$ is famous for his three laws of planetary motion. Although they are based on observations (discrete numerical data), Kepler used significant mathematics to establish them. For 
the first law, he used interpolation and extrapolation to fit possible curves to the planetary position. At the start of his explorations into the difficult orbit of Mars these curves were traditional circles (whose centres were offset from the Sun), then he tried an egg-shape, and then successfully an ellipse. The area law was inspired by his earlier work in volumes of revolution, by subdividing the body into $n$ thin slices, indexed by integer $r$, and then summing from $r=1$ to $r=n$ an expression for the volume of the $r^{\text {th }}$ slice. He was able to do the same for areas swept out by a planet over time, dividing the interior of the orbit into thin triangles whose vertices are the Sun and two neighbouring positions of the planet (either observed or interpolated).

We now return to Kepler's work. K presented his methods and preliminary calculations in the Epitome [6]. It contains a description of the Copernican heliocentric model of the solar system, Brahe's model, and K's own mathematics. The Epitome embraces the new idea of logarithms, invented by John Napier [1550-1617]. K read Napier's account of his discovery of logs soon after its publication in 1614 [7]. In $1617 \mathrm{~K}$ warmly praised Napier's discovery of logs in a letter which sadly arrived after Napier had died. Realising the saving in time that logs brought to arithmetic, $\mathrm{K}$ recorded his own understanding of the subject - a work he later published [8]. See [2] p309 and the scholarly comments on Kepler's presentation of logs by Hutton [9]. Hutton reproduces a sample of K's table of logs, included in the Rudolphine Tables.

Veteran readers may also remember learning about log tables any time up to the 1970s, using a similar routine $\mathrm{K}$ taught himself. For the sake of readers schooled in electronic calculators alone, the method goes as follows. Suppose a number $x$ is to be multiplied by a factor $f$ to obtain their product, $p=x f$. The $\log$ of the answer is $\log p=\log (x f)=\log (x)+\log (f)$, which is just the sum of two entries looked up in a log table. Finally, instead of calculating the inverse function (exponentiating), one looks into the body of the $\log$ table to find the number $p$ whose $\log$ is listed as $\log p$. When multiplying a column of numbers $x$ by a fixed factor $f$, this saves much time, compared with K's other options - an abacus or long-multiplication on paper. K routinely dealt with numbers of 6 to 8 significant figures. It was the saving of time that popularised logs among astronomers. Linton [1] writes more on this, and quotes a letter of $\mathrm{K}$ claiming that arithmetic which formerly took months was reduced by logs to days.

Publication of the Epitome was completed in 1621, and it raised more demands that K get on with publishing the Rudolphine Tables. The Catholic Church immediately put the Epitome on its Index of Prohibited Books. Nevertheless, it eventually became "the most widely read astronomical work in Northern and Western Europe", [10]. The need for improved astronomical tables was pleaded by several professions: astronomers for observations of stars, astrologers for making star charts at a client's time of birth; navigators and explorers for plotting courses and positions at sea (usually from a few briefly visible stars); cartographers for authoritative positions of cities and geographical features; instrument-makers for the correct numerals to engrave on their wares; self-employed teachers of apprentices, needing to read about the new learning. Inaccuracies in the old Alphonsine and Prutenic Tables (based on data of Ptolemy, Copernicus, Longomontanus) led to forecasting errors of up to $5^{\circ}$ in planetary positions. This is an enormous error compared with say the diameter of the Moon, which subtends about $0.5^{\circ}$ (the tip of your little finger at arm's length can cover the Moon!). K achieved a much better accuracy of $0.05^{\circ}$. For the position of Mars in its orbit this was acceptable in 17th and 18th centuries. But by comparison we should note that when it is nearest the Earth, the diameter of Mars subtends only $0.005^{\circ}$.

$\mathrm{K}$ possessed Tycho Brahe's measurements of star and planetary positions, so the duty rested on his shoulders to deliver the Rudolphine Tables. The Brahe family were jealous, prickly and suspicious throughout. Even in their astronomical ignorance, the Brahes saw a prospect of profit and glory from K's labours. We see more of their interfering in K's work below.

\section{The Making of the Tables}

The manuscript of the Tables was nearing completion towards the end of 1624, and $\mathrm{K}$ had to plan ahead for a difficult printing job. The book has 120 pages of text and 119 pages of tables. The tables were hard to typeset accurately. How could he do it? First K sought his back-pay as Imperial Mathematician 
to the Catholic Emperor Ferdinand II. (K was a devout Protestant.) What he received was a royal promise that he be paid 6000 gulden of the 12000 owed K. The promise was only an order for K to be paid by three German cities, to which he had to travel in December 1624: Nuremberg (3966 gulden), Memingen (1297 gulden) and Kempten (936 gulden). He'd already lost 4 months of waiting at court. The Emperor vetoed his wish to print the work in Ulm, and insisted upon the work being issued from a press in Austria, at Linz. This instruction caused K much trouble and danger. During his inter-city travels he paid for four bales of paper ( 2 ordinary and 2 finer quality) and had them sent to Linz. He sought skilled typesetters, and recruited a Protestant printer with apprentices. He cast his own characters for the planetary symbols which were needed as space-saving devices in the Tables.

$\mathrm{K}$ had been living in Linz for 14 years with his wife and children, when troubles began for citizens. All Protestants were ordered out of the city, but with the help of his friends $\mathrm{K}$ was exempt, as were his Master Printer and apprentices. Nevertheless, K was suspected of heresy and asked to give up his library for inspection. After a cursory look the counsellors passed him and his books, as orthodox. They even sought his advice about the protection of Linz's provincial library in case of fire or flood - his advice was to pack the books into wine barrels so that they could be rolled to safety [4].

The work to print the Rudolphine Tables began, and K spent much time at the print shop, proofreading the sheets as they came off the press, and marking corrections.

As part of the Thirty Years War, Linz was garrisoned by Bavarian soldiers. Some were billeted on the print shop, situated on the city's wall. Above the shop was a wall rampart patrolled by soldiers. Lutheran small-farmers besieged Linz from June to August 1626. Plague and famine followed. In a letter K described looking out over the walls at the besieging forces; the noise of cannon disturbed his work by day; the comings and goings of soldiers disturbed his sleep by night. However, the work proceeded, until 30 June 1626 when the besiegers caused a fire which grew to burn 70 houses, including the print shop. All the printed sheets were destroyed, but K's manuscript survived. (Perhaps the printer could have taken K's earlier advice and packed the sheets into wine barrels.)

After the fire $\mathrm{K}$ had to wait more weeks while the siege continued. The liberation of Linz finally came when Imperial troops arrived in early August. The printing-house disaster forced him to quit Linz for Ulm, taking with him his wife Susanna (neé Reuttinger) and their three children: Cordula aged 5, Fridmar aged 3, and 1-year-old Hilderbert. K left his family in safety at Regensburg and rode on to Ulm, where at last he was able to settle down to start all over again. He engaged another Master Printer, Jonas Saur (a name meaning 'sour'), and he daily visited Saur's print shop just across the street from his lodgings. He now designed an image for the frontispiece, helped by an artist to work up a sketch for the engraver (one Georg Celer of Nuremberg). K included himself in the design, sitting calculating at a table in a basement, with hoped-for payment in coins falling down to him. (See figs 22.2, 22.3 [3].) K's habit of proof-correcting sheets as they came off the press irritated Saur and they quarrelled. Irritation on both sides came to a head in February 1627, when K rode out of Ulm in a great huff, intending to start again at Teubingen, 50 miles away. He was riding in cold winter weather, and he had boils on his backside. His temper cooled and, after 15 miles, K turned back towards Ulm. There, he and Jonas Saur made up their differences, and from then on the work went more smoothly. The eventual print run was 1000 folio copies. The work was mainly done during the Spring and finally completed by early September 1627. Rather late, the Brahes complained about K's printed preface, which was longer than the one Tycho's brother Georg had written. K edited his preface and put Tycho as first author, as it was the crowning achievement of both their lives.

Presumably, it took time to bind some of the copies for sale. It was common practice in Europe for newly printed books to be sold with covers made from paste board or thick paper, or no covers at all. It was expected that a purchaser would have a bespoke binding made, to suit the new owner's tastes. All this preparation was in readiness for the annual Frankfurt Book Fair, still held annually.

At this stage K turned his hand to book-selling. Arriving at Frankfurt on 22 September, he wanted to sell the Tables at 5 gulden per copy, and he had the backing of Jesuit pricing specialists. But the pretentiously titled Imperial Book Commissar set the prices at 3 gulden for the cheap-paper copies, and 
3 gulden 40 kreuzers for those printed on luxury paper. All this was done rather late while the official fair was ending on 2 October. The lateness was to K's advantage though, as he gained time to publicise his completed work, to build even better demand. A book dealer known to have bought copies at the Fair, is Gottfried Tampach, of Frankfurt. K kept back some complementary copies, presumably bound in presentation bindings, to send to his learned friends abroad, e.g. to Matthias Bernegger of Strassburg, who was in contact with interested university teachers there. The Brahe family were still arguing over the length of K's preface, so much so that there are 3 distinct printed versions of these pages among surviving copies of the Rudolphine Tables, so to speak of a "first edition" is a complicated bibliographical problem.

A bibliographical description of Tabulae Rudolphinae is as follows: written and printed in Latin at Ulm by J.Saur; a large folio $(348 \times 230 \mathrm{~mm})$ of 120 pages of prose text; a further 119 pages of astronomical tables; positions of 1008 stars; descriptions of methods for locating all the planets hundreds of years in the past and into the future; many cities' latitude and longitude coordinates are listed with respect to the meridian of Hveen (Tycho's island observatory). On 27 April 2020 one antiquarian book dealer was offering a copy for sale for about $£ 50,000$ sterling ( $\$ 60,000$ US). See [11].

\section{The Legacy of the Published Rudolphine Tables}

After the Frankfurt Book Fair, K travelled home to Ulm, arriving 9 November 1627, and he stayed to celebrate the Christmas festival with family. During the festival period, he rode to the imperial court, then at Prague, where he wanted to give a presentation copy of the Tables to the Emperor, and plea for his back-pay. Emperor Ferdinand II was celebrating Christmas, and K did receive some court patronage, from General Albrecht Wallenstein, a recently successful commander in the Thirty-Years War, on a campaign in Denmark. Wallenstein gave K a salary of 1000 florins and a house in the town of Sagan. K lived peacefully there with his family, and he and Susanna celebrated the birth of another daughter. These were the last years of K's life, up to 1630, and he was able to live with Protestant neighbours under General Wallenstein's protection. Nevertheless, K became unhappy in Sagan: perhaps he felt that his best work was behind him, and he worried about what would happen to his family after his death. As it turned out, K's works in print were a long legacy of financial and moral support for Susanna (who was 17 years younger than K), and for their children. There are more details of K's family life in [3].

In $1629 \mathrm{~K}$ used his findings from the Epitome and the Rudolphine Tables to predict a transit of Venus - a rare crossing of the Sun's disc by the planet - due on 7 November 1631. Subsequently he wrote a pamphlet about his forecast, one of his last publications. $\mathrm{K}$ did not live to see his prediction come true. A contemporary astronomer, J.B. Riccioli, made his own calculations with the Rudolphine Tables, and was the first to report observations of a transit of Venus, made on the very day K predicted. K's timing of the start of transit was only a few hours in error, an improvement on previous errors of days for planetary conjunctions. (For more on this see Linton [1], who explains why they are rare and how transits of Venus usually occur in pairs separated by eight years.) One of many influences of K's work was on the Silesian astronomer Maria Cunitz (Latin Cunitia) [1610-1664], whose own book of planetary tables was published in 1650. For more on the influence of the Epitome and Tables on astronomers in the 17th century see Russell [10].

Kepler's scientific legacy endures today in his important mathematical discoveries of three laws of planetary motion. The fame of Tabulae Rudolphinae rests on their accuracy and usefulness for at least a century after K's death in 1630. The work was only superseded by astronomers working with quadrants fitted with telescopic sights, with which astronomers could make measurements 100 times more precise than naked-eye estimates. But this increased accuracy multiplied the work of preparing new tables for publication. For example, consider the great labour of John Flamsteed [1646-1719], who repeatedly checked star-positions over decades, with the best instruments in England, at the Greenwich Observatory. His endeavours eventually led to the publication (with others) of a 3000-star catalogue Historia coelestis Britannica during 1712-25. Like the chorus of demands that K must publish his tables, Flamsteed was pestered with demands from Isaac Newton, Edmund Halley and others pleading he release his data to help 
accelerate important research. Newton wanted them for Principia, and Halley wanted data to confirm his theory of the orbits of comets, and predict the next return of what we now call Halley's Comet.

It is to the credit of Johannes Kepler, John Flamsteed and later astronomers, that they persevered to publish celestial data and their mathematical methods, for the direct benefit of practitioners, and for the long-term safety of map-users, crews and passengers voyaging all over the world.

Acknowledgments: The author thanks the staff of local grocery stores who served communities, often in peril of their lives, during the recent Covid-19 Pandemic. The author also thanks Prof. Shaun Stevens for his help and leadership of the School of Mathematics, University of East Anglia, during the Pandemic.

\title{
References
}

[1] C.M. Linton 2007 From Eudoxus to Einstein: a history of mathematical astronomy. Cambridge University Press, 220-230.

[2] M. CASPAR 1959 Kepler. London, Abelard-Schuman, 318-328.

[3] K. FERGUSON 2002 Tycho and Kepler: the strange partnership that revolutionised astronomy. London, Headline Publishing, p346-357 and figs 22.2, 22.3.

[4] A. Koestler 1968 The Sleepwalkers. Penguin Books, 411-416.

[5] J. KePLer 1627 Tabulae Rudolphinae. Ulm., Jonas Saur, folio.

[6] J. KePleR 1618-21 Epitome of Copernican Astronomy. Johannes Planck, Linz \& Frankfurt. [Translated C.G. Wallis, Great Books of the World 16, Encyclopaedia Britannica, Inc., 1952.]

[7] J. NAPIER 1614 Mirifici logarithmorum canonis descriptio. Edinburgh, A. Hart, quarto.

[8] J. KePLER 1624 Chilias logarithmorum. Chemlin, 1624, 103 pages.

[9] C. Hutton 1794 Mathematical Tables. London, G.G. \& J. Robinson and R. Baldwin. p31-33.

[10] J.L. RuSSELl 1964 Kepler's Laws of Planetary Motion: 1609-1666. British Journal for the History of Science, 2(1), 1-24.

[11] W.P. WATson AntiQuARIAn Books, 2020 London, United Kingdom.

\author{
MARK J. COOKER \\ School of Mathematics, \\ University of East Anglia, \\ Norwich NR4 7TJ, UK \\ E-mail: m.cooker@uea.ac.uk
}

